\title{
Aos filhos de Foucault ${ }^{*}$
}

O livro aqui resenhado foi originalmente apresentado como tese de doutorado, por Antonio Crístian Saraiva Paiva ${ }^{1}$, no Programa de Pós-Graduação em Sociologia da Universidade Federal do Ceará, sob orientação de Daniel Lins, em setembro de 2004. Ao longo de suas 368 páginas, somos conduzidos pelo autor aos meandros do intensivo, microscópico, molecular, artesanal e marginal mundo dos experimentos relacionais clandestinos do amor entre homens. Com forte inspiração foucaultiana, o olhar de Paiva, que também é analista lacaniano experimentado na clínica, propõe uma sociologia das tempestades e dos interstícios para descortinar as vidas de dez casais de "homens infames", moradores de Fortaleza, vinculados amorosa e sexualmente por relacionamentos de longo prazo. A proposta do autor é fazer uma escrita proximal $e$ intensiva, que concede a palavra a seres invisíveis e escreve as biografias de humanos anônimos, assumindo os riscos de um fazer etnográfico que está na fronteira entre organizar confidências e arregimentar confissões.

Para Paiva, o fundamental da escuta-visão-escrita de seu fazer sociológico não está na busca de categorias totalizantes ou

\footnotetext{
* Resenha do livro de Antonio Crístian Saraiva Paiva, Reservados e invisíveis - o ethos íntimo das parcerias homoeróticas, 2007. Recebida para publicação em fevereiro de 2008, aceita em abril de 2008.

** Sociólogo, Professor Adjunto do Departamento de Ciências Sociais e do Programa de Pós-Graduação em Sociologia da Universidade Federal de Goiás; Coordenador do Ser-Tão, Núcleo de Estudos e Pesquisas em Gênero e Sexualidade. luizman@gmail.com

1 Paiva também é autor de Sujeito e laço social (Relumé-Duramá, 2000) e coorganizador, com Alexandre Fleming Câmara Vale, de Estilísticas da Sexualidade (Programa de Pós-Graduação em Sociologia da Universidade Federal do Ceará/Pontes Editores, 2006).
}

cadernos pagu (30), janeiro-junho de 2008:427-435. 
Aos filhos de Foucault

de atributos identitários capazes de explicar o mundo relacional dos sujeitos com os quais conviveu ao longo de dezenas de horas de contato com seu mundo familiar e social e quase cem entrevistas individuais e em casal. Antes, seu objetivo principal é realizar uma sociologia da reserva, da discrição e da invisibilidade, que capta os mecanismos sutis de construção das micropolíticas do cotidiano dos casais e das formas de cuidado de si e do outro. Longe da pretensão de descortinar essências ou verdades intrínsecas às dinâmicas homoconjugais, Paiva faz de seu texto um convite à compreensão dos mecanismos de gestão da poética do amor e da paixão, na perspectiva de sujeitos muitas vezes desprovidos de palavra/lugar para enunciar e viver desejos, afetos $e$ amores ainda vistos em grande medida como patológicos, desviantes e imorais, para não dizer sub-humanos. Como destaca o autor, não se trata de histórias de amor ou de vida de seres excepcionais, mas o que as torna singulares, e especiais, é exatamente sua banalidade, sua falta de heroísmo, sua trivialidade, sua convergência com o que há de mais ordinário no amor entre humanos, ainda que viver homossexualmente, em meio à homofobia prevalecente - no Ceará, no Brasil e no mundo -, seja quase sempre um exercício de bravura e valentia. Num cenário assim marcado, duas questões principais nortearam o interesse de Paiva pelas histórias de amor que reúne em seu livro: "Como conduzir a existência a dois, livre dos constrangimentos institucionais, livre dos cimentos sociais, sem vocabulário específico para poder falar positivamente de suas transações erótico-amorosas? O que podem fazer dois homens juntos?" (270).

Além de introdução e conclusão, o livro estrutura-se em treze capítulos (alguns curtinhos, com não mais que poucas páginas), distribuídos em quatro partes: 1) Dobras da intimidade: as margens conceituais; 2) Ensaio de etno-sociologia da intimidade (metodologia \& etnografia); 3) Estilísticas da existência: gestão das amizades particulares; e 4) Homossexualidade e estética da existência: por outras cartografias e laços. Com esses títulos não é difícil perceber algumas influências teóricas 
fundamentais - Derrida, Deleuze, Guattari e, especialmente, Foucault, entre muitos outros -, que fornecem a base dos conceitos utilizados nas reflexões sobre a economia sentimental dos homens que integram a amostra intencional. A primeira parte do livro, assumidamente conceitual, faz do diálogo com as sociologias de Giddens, Bourdieu e Simmel ponto e partida no trabalho de (re)situar o debate sobre as relações entre homossexualidade e conjugalidade, por um lado, e potencialidade orgiástica e normalização dos desejos, por outro, preocupação recorrente do autor.

Um dos referentes centrais da argumentação de Paiva é a concepção foucaultiana que vincula homossexualidade masculina à amizade e compreende as relações amorosas e sexuais entre homens como laboratórios de experimentação $e$ reencarnação do desejo e das práticas de liberdade, para além dos limites da norma heterocêntrica e do arbítrio do Estado. No esforço de caracterização das histórias amorosas de seus entrevistados, Paiva utiliza-se das clássicas categorias de Foucault para mostrar como os sujeitos constroem sua conjugalidade na fronteira entre a recriação do mundo a partir de uma nova ética amorosa e sexual e a reprodução dos elementos constitutivos da matriz heterossexual: fidelidade, complementaridade, eternidade. Mas o que diria Foucault se estivesse vivo hoje, quase vinte $e$ cinco anos após sua morte, num momento em que a aids já fez uma longa carreira de epidemia mortal à doença crônica e no qual a conquista de direitos conjugais e parentais tornou-se a principal reivindicação política de gays e lésbicas nos países em que a homossexualidade não é tipificada como crime? Em relação às lésbicas, há um silêncio, em Foucault e em Paiva, sobre eventuais parâmetros libertários de sua sexualidade, mas o inconteste é que mundo afora não se ouve falar de sexo entre mulheres em saunas, parques, quartos escuros de boates ou banheiros públicos de shopping centers - práticas minoritárias, mas reais, que alimentam o imaginário transgressor, supostamente intrínseco ao erotismo entre homens. Para lésbicas, ao contrário, o revolucionário de sua 
Aos filhos de Foucault

sexualidade estaria fundado na ruptura com dois pilares sagrados da matriz heterossexual: a hipervalorização do falo e o coitocentrismo.

Recorrendo a trechos de Em busca do tempo perdido, de Marcel Proust - e também a fragmentos de Grande Sertão: Veredas, de Guimarães Rosa - para vez ou outra ilustrar a etnografia da invisibilidade que realiza, Paiva apresenta os regimes de luz e palavra que estruturam as vivências amorosas de seus homens duplamente sem rosto (pelo anonimato das entrevistas $e$ por sua invisibilidade social) e propõe a realização de um exercício de "estética da existência miúda" ao olhar para os retratos e arquivos de suas vidas. Em sua construção de uma topologia da intimidade, que busca compreender a economia do silêncio e do segredo, Paiva recusa o "modelo da concha", a perspectiva euclidiana da oposição dentro-fora e opta pelo sentido deleuzeano da dobra que constitui o si como forro. Vista pelo autor como assunto de feitiçaria, sua metodologia advoga a lógica do contágio e dos contrabandos, produzida por um sociólogo andarilho, que mergulha na noite em busca da "fala dos passos perdidos", as biografias conjugais de seus entrevistados.

A imagem da "tina dos encontros" é a utilizada por Paiva para descrever a intervocalidade típica dos espaços de audição interlocução que estabeleceu com os casais cujas vidas evoca. Nega-se a clássica distância entre entrevistador e entrevistado. A intenção, ética, estética e poética, é construir "anti-histórias" e "contra-arquivos" dos amores incitados a dizerem seus nomes seus riscos, suas perdas, seus custos, suas conquistas, seus prazeres, suas descobertas -, sem tomá-los como representação sociológica de uma tipologia do casal homossexual. Com escrita leve e pena de romancista, Paiva atua como porta-voz altivo das histórias de reconhecer-se homossexual, constituir-se como sujeito desejante, sobreviver na selva da homofobia onipresente, reinventar uma conjugalidade que não comporta a homossexualidade na matriz original $e$ administrar as alegrias $e$ dissabores típicos das histórias de amor. Esse momento de 
apresentação das vidas paralelas dos homens infames, que literalmente abriram seus baús, armários, casas e corações ao autor, talvez seja o que há de mais impactante e tempestuoso no livro. Não que as aproximações teóricas de Paiva sejam desinteressantes ou que seus registros do fazer metodológico inovem pouco. Ao contrário. Ler Reservados e invisíveis é ter acesso a reflexão teórica e a compromisso metodológico transgressores e sofisticados. Mas não há melhor resposta à pergunta de Paiva, "o que fazem dois homens juntos?", do que as correntes e torrentes de afeto, desejo, medo, esperança, desespero, ilusão, alienação, busca, solidão, partilha e prazer de seus entrevistados, quando falam dos cuidados de si e com o outro.

Contudo, ao apresentar os mundos de seus casais de homens sem rosto, idade, profissão, classe social, raça, religião $e$ outros atributos identitários, Paiva não tem como escapar ao uso de sua posição privilegiada de sociólogo criador de vidas para escolher as características e fatos que prefere destacar - e como ordená-los - e para selecionar as palavras a partir das quais os descreve. Em algumas partes do texto é difícil saber se estamos diante de uma narrativa ou descrição feita pelo autor ou de uma reprodução literal das falas dos sujeitos sobre si próprios e suas vidas de casal. Em outros trechos, não se sabe qual dos dois membros da díade está falando, numa simbiose narrativa talvez intencional, mas também talvez decorrente da dinâmica relacional do casal, em que um deles fala quase tudo e o outro ouve, repete, ecoa ou discorda, mas silencia. Nas histórias que narra, Paiva enfatiza - às vezes excessivamente - os momentos de saída do armário e os conflitos familiares e sociais daí decorrentes, sem ater-se exclusivamente às cartografias do desejo, às etnografias dos prazeres, às genealogias das promessas $e$ às topografias das desilusões.

No universo dessas histórias conjugais, Paiva proporciona ao leitor vôos panorâmicos - e também rasantes - sobre os pactos quanto à fidelidade, as negociações de papéis sexuais, a 
Aos filhos de Foucault

administração do segredo em relação à homossexualidade e à vida de casal, as posições políticas geralmente pouco engajadas, a relativa prevalência de discursos depreciativos em relação aos iguais, o silêncio quase generalizado quanto à aids, o heterocentrismo que impregna as concepções de família e tantas outras coisas mais. Paradoxalmente, ainda senti falta de carne $e$ vida nas descrições. Como eram os homens entrevistados - física, psíquica e intelectualmente? De que cor e tamanho eram suas casas? Como administravam a questão do dinheiro no âmbito do casal? Algum dia pensaram em ter filhos? Quais seus sonhos e planos para o futuro? Como se sentem em relação ao mundo de silêncio e reserva em que vivem? Apesar dessas e outras lacunas, Paiva é meticuloso na apresentação de "seus" homens, cuidadoso no contrabando das informações de suas vidas, apaixonado mesmo na reconstrução dos registros de suas intimidades $e$ absolutamente feliz na maneira como os apresenta: exagerados em seus pontos de vista, mesquinhos na justificação de suas razões, ansiosos por uma normalidade que a sociedade lhe nega, humanos em suas contradições.

$\mathrm{Na}$ quarta e última parte do livro, as questões centrais que orientam as reflexões de Paiva sobre os amores masculinos são outra vez de matriz foucaultiana:

(...) que experimentações, que devires, quais "novos" modos de vida vão-se configurando? Que deslocamentos vão efetuando no repertório de nossas modalidades relacionais institucionalizadas? (279).

No contexto dessas indagações, o autor também se pergunta sobre os significados do "desejo de normalização" que parece prevalecer nos debates políticos - e acadêmicos? - sobre homoconjugalidade e homoparentalidade. Mas Paiva não cai na cilada fácil de entender que todo desejo de reconhecimento legal de direitos conjugais e parentais é sinal de conformismo e perda do potencial disruptor do erotismo entre homens. Ao contrário, 
acredita que a força subversiva desses experimentos conjugais possa emergir no interior mesmo dos debates políticos sobre conjugalidade entre pessoas do mesmo sexo, quando se rompe com essencialismos e são abertas linhas de fuga em direção a possibilidades não hegemônicas de vivência da amorosidade e da sexualidade, convergentes com as idéias guattariana de nova suavidade e deleuziana de devir-homossexual.

Especialmente interessante e merecedor de destaque nesta quarta parte do livro é o capítulo intitulado "Destinos da homossexualidade no arquivo psicanalítico". Nele estão, sobrepostos, os Paiva sociólogo e psicanalista, que colocam sob lupa potente as perspectivas de Freud e Lacan sobre a diferença sexual $e$ a homossexualidade. Enquanto a obra freudiana é apresentada, talvez otimistamente demais, como responsável pela libertação da sexualidade humana do registro da anatomia, da reprodução e da etologia, o olhar lacaniano é referido como marcado por dois equívocos que assumem a forma de pressupostos: a definição da homossexualidade como perversão $e$ a associação da diferença sexual à heterossexualidade. Contundentes e estimulantes são as críticas apresentadas por Paiva a esse olhar heterocêntrico de Lacan e seus seguidores, ótimos pontos de partida para a compreensão do lugar conservador e reacionário assumido pela psicanálise nos debates políticos $e$ acadêmicos sobre conjugalidade $e$, particularmente, parentalidade de gays e de lésbicas. Não é demais lembrar que em fins dos anos 90, quando na França se discutia o projeto de lei que culminou com a aprovação do Pacto Civil de Solidariedade, psicanalistas e católicos estiveram lado a lado na defesa da família tradicional como pré-requisito fundamental da vida em sociedade - "ordem simbólica" e "natureza" foram categorias-chaves e quase intercambiáveis entre aqueles que acreditavam que a presença de um casal formado por um homem e uma mulher é pré-requisito básico e estruturante da inserção simbólica e material das crianças no mundo social. 
Aos filhos de Foucault

Não restam dúvidas de que Reservados e invisíveis é um livro que deve ser lido. Antes de tudo, por sua originalidade e bom texto, mas também e especialmente pela dramaticidade e urgência das questões que trata. Quase todos sabem que o mundo dos amores e dos prazeres sexuais não é o terreno das felicidades $e$ alegrias eternas que querem nos fazer acreditar desde crianças, sejamos a, bi, homo, hetero, pan ou simplesmente sexuais. As violências das desilusões, desencontros, rupturas e abandonos são muito mais freqüentes do que os encantamentos e êxtases dos poucos momentos de contos de fadas que cada um de nós tem na vida. Mas por trás dessa constatação comum a todos, outra realidade singular a um grupo específico de pessoas é descortinada neste livro: as trágicas, cotidianas, banalizadas $e$ naturalizadas conseqüências da homofobia. São casais de homens que vivem juntos há muitos anos, mas que, na maioria das vezes, fingem ser apenas bons amigos perante suas famílias, amigos, colegas de trabalho, vizinhos e conhecidos em geral. Para além de uma bolha de segurança formada por um restrito grupo de amigos, esses homens vivem sua infâmia na vergonha do anonimato, no esconderijo dos beijos nunca trocados em público, no silêncio dos prazeres e dores sem uma voz que os enuncie livremente. Silêncio, por sinal, é uma palavra-chave em seus mundos, numa versão nacional e civil da política das forças armadas dos EUA em relação à homossexualidade: "Don't ask, don't tell" - Não pergunte, não diga.

Livros como o de Paiva, seguramente, são fundamentais quando se pensa em uma ciência compromissada, ética e politicamente, com o fim deste cenário de silêncios, reservas e invisibilidades, quando menos porque contribui para que a reivindicação de direitos civis para casais de gays e lésbicas deixe de ser vista como um ataque inaceitável às leis de deus, da natureza e dos homens - na versão mais virulenta da intolerância - ou como sinal de decadentismo burguês e domesticação dos prazeres - na versão mais erudita da homofobia neoliberal. Não tenho dúvidas de que o mundo da heterossexualidade tem muito 
a aprender com as delícias dos espaços lúdicos de camaradagem sexual masculina, mas também penso que os filhos de Foucault precisam ter o irrestrito direito à liberdade dos amores e prazeres sexuais vividos abertamente, em plena luz do dia, sem medo do insulto ou do ataque físico, contando com a devida proteção legal e legitimidade social. 